University of Nebraska - Lincoln

DigitalCommons@University of Nebraska - Lincoln

Faculty Publications from the Harold W. Manter Laboratory of Parasitology

2001

\title{
Prevalence of Eimeria (Apicomplexa: Eimeriidae) in Reintroduced Gunnison's Prairie Dogs (Cynomys gunnisoni)
}

\author{
M. M. Ryan \\ University of New Mexico, mryan@unm.edu \\ K. H. Decker \\ University of New Mexico \\ Donald W. Duszynski \\ University of New Mexico, eimeria@unm.edu
}

Follow this and additional works at: https://digitalcommons.unl.edu/parasitologyfacpubs

Part of the Parasitology Commons

Ryan, M. M.; Decker, K. H.; and Duszynski, Donald W., "Prevalence of Eimeria (Apicomplexa: Eimeriidae) in Reintroduced Gunnison's Prairie Dogs (Cynomys gunnisoni)" (2001). Faculty Publications from the Harold W. Manter Laboratory of Parasitology. 635.

https://digitalcommons.unl.edu/parasitologyfacpubs/635

This Article is brought to you for free and open access by the Parasitology, Harold W. Manter Laboratory of at DigitalCommons@University of Nebraska - Lincoln. It has been accepted for inclusion in Faculty Publications from the Harold W. Manter Laboratory of Parasitology by an authorized administrator of DigitalCommons@University of Nebraska - Lincoln. 


\title{
Prevalence of Eimeria (Apicomplexa: Eimeriidae) in Reintroduced Gunnison's Prairie Dogs (Cynomys gunnisoni)
}

\begin{abstract}
Fecal samples from 54 Gunnison's prairie dogs (Cynomys gunnisoni) from Albuquerque, NM were analyzed for the presence of coccidia and all were positive. They were then relocated to an abandoned prairiedog town on the Sevilleta Long Term Ecological Research (LTER) site. Six Eimeria species, E. callospermophili, E. cynomysis, E. pseudospermophili (new host record), E. spermophili, E. ludoviciani and E. vilasi (new host record) were found in Albuquerque animals, but only 2 species, E. callospermophili and E. vilasi were present in relocated hosts. A significant $(\mathrm{P}<0.05)$ reduction was seen in the prevalence of E. vilasi $(72 \%$ vs. $13 \%)$ and in the prevalence of infections $(\mathrm{P}<0.05)$ with 2 or more Eimeria species $(39 \%$ vs. $4 \%)$ in pre- and postrelocation animals. To assess the impact of the introduction of $C$. gunnisoni on the resident rodent population, feces were collected from 6 species of rodents. Five Eimeria species, E. arizonensis (Reithrodontomys), E. chobotari (Dipodomys, Perognathus), E. liomysis (Dipodomys), E. mohavensis (Dipodomys) and E. reedi (Perognathus) were found. We found no evidence of coccidia transfer among introduced and resident rodent species.
\end{abstract}

\section{INTRODUCTION}

Prairie dogs are an important part of the grassland systems of North America and with $98 \%$ of their historic original population already destroyed due, in part, to habitat loss, they are prime candidates for relocation efforts (Miller et al., 1994; Long, 1998). Here we document the coccidia fauna of a population of Gunnison's prairie dogs (Cynomys gunnisoni, Baird 1855) that was relocated from Albuquerque to an abandoned prairie dog town on the University of New Mexico's (UNM) Long Term Ecological Research (LTER) site within the Sevilleta National Wildlife Refuge (SNWR) near Socorro, $\mathrm{NM}$, as well as that of the dominant rodent populations resident near the reoccupied prairie dog town on the Sevillea. Little is known about prairie dog parasite communities and the influence their presence may have on the parasite communities of sympatric rodent species.

Eimeria spp. have a direct life cycle that is easily monitored by the noninvasive examination of fecal pellets, which allows the least interference and stress in a relocated host population. Eimeriid coccidia are known to be reasonably host specific, transferring easily between congenerics (Upton et al., 1992; Seville, 1997; Hnida and Duszynski, 1999), infrequently among confamilials (Todd and Hammond, 1968a, b; Wilber et al., 1998) but only rarely between families or orders (De Vos, 1970; Hendricks, 1977). The objectives of this study were to: (1) survey the coccidia species infecting C. gunnisoni and the dominant species of the resident rodent population and (2) compare the prevalence of infections with coccidia of $C$. gunnisoni and the major rodent residents before and after relocation.

\section{MATERIAL AND MeTHODS}

Sixty prairie dogs (54 fecal samples collected) were captured at three localities on 29 March and 16, 18 April 1997, within the Albuquerque (Bernalillo County) city limits, marked with a passive integrated transponder (PIT) and relocated the same day to an abandoned prairie dog colony on the Sevilleta LTER in central New Mexico $\left(34^{\circ} 12^{\prime} 56^{\prime \prime} \mathrm{N}, 106^{\circ} 47^{\prime} 3^{\prime \prime} \mathrm{W}\right.$, elevation = $\left.1536 \mathrm{~m}\right)$ (Davidson et al., 1999). Twenty-nine of those prairie dogs (23 fecal samples collected) were recaptured during subsequent trapping on 15, 16, 17 July. For further details of animal processing and methods of colony reestablishment see Davidson et al. (1999).

Rodents on the Sevilleta LTER were captured with Tomahawk ${ }^{\sqrt{10}}$ live traps placed every $10 \mathrm{~m}$ in a $100 \times 100 \mathrm{~m}$ grid. Rodents were trapped on 6 grids and feces were collected on 3 prerelocation dates, 11, 12, 13 March and 6 postrelocation dates, 6, 7, 8 May, 8 July and 17, 19 September 1997; 3 grids were located on the prairie dog town (treatment sites) and 3 grids were located across an arroyo approximately 50-200 m away (reference sites) (Davidson et al., 1999). Animals were presumed to not cross this arroyo.

Feces collected from each animal were put into a solution of $2 \%$ aqueous (w/v) potassium dichro- 
TABLE 1.-Prevalence (\%) of Eimeria spp. in fecal samples of Gunnison's prairie dogs, Cynomys gunnisoni, in Albuquerque (March 1997) and on the Sevilleta LTER (July 1997) after 60 animals from Albuquerque were relocated to an abandoned prairie dog colony on the LTER

\begin{tabular}{lcc}
\hline \hline & \multicolumn{2}{c}{ No. infected hosts (prevalence) } \\
\cline { 2 - 3 } \multicolumn{1}{c}{ Coccidian spp. } & $\begin{array}{c}\text { March samples } \\
\text { prerelocation }(\mathrm{n}=54)\end{array}$ & $\begin{array}{c}\text { July samples } \\
\text { postrelocation (n }=23)\end{array}$ \\
\hline E. callospermophili & $33(61)$ & $8(35)$ \\
E. cynomysis & $2(4)$ & - \\
E. ludoviciana & $1(2)$ & - \\
E. pseudospermophili & $3(6)$ & - \\
E. spermophili & $1(2)$ & $2(9)^{*}$ \\
E. vilasi & $39(72)$ & $4(17)$ \\
Unsporulated & $4(7)$ & $15 / 23(65) *$ \\
Multiple infections & $25(44)$ & - \\
All species & $54 / 54(100)$ & \\
\hline
\end{tabular}

* Postrelocation prevalences were significantly lower $(\mathrm{P}<0.05)$ than those of prerelocation population

mate and taken to the University of New Mexico where oocysts were allowed to sporulate; oocysts were isolated, identified, measured and stored following Duszynski and Wilber (1997).

Prevalence (no. infected hosts/no. hosts collected) of each eimeriid species in the prairie dog and rodent sample populations was calculated before and after relocation. A $t$-test (95\% confidence interval) for two independent binomial samples was used to assess significant change in eimeriid prevalence between pre- and postrelocation populations (Christensen, 1996). We tested the null hypothesis for no difference in eimerian prevelance between populations.

\section{RESULTS}

All $54(100 \%)$ fecal samples collected from prairie dogs in Albuquerque in March and April 1997 had eimeriid oocysts (Table 1). Because no significant difference was found in eimerian prevalence among the original three subpopulations of prairie dogs $(\mathrm{P}>0.05)$, they were combined into a single prerelocation population in later statistical analysis. Prerelocation prairie dogs had a significantly $(\mathrm{P}<$ 0.05) higher prevalence of infection with coccidia than did postrelocation animals. Prevalence of $E i-$ meria vilasi and of multiple infections also was significantly greater $(\mathrm{P}<0.05)$ in the prerelocation population (Table 1).

Fecal samples also were obtained from 391 individual animals of the 6 dominant species of rodents on the Sevilleta LTER, including Dipodomys ordii (21), D. spectabilis (16), Onychomys arenicola (8), Perognathus flavus (320; mean recapture level $=18 \%)$, Peromyscus leucopus (14) and Reithrodontomys megalotus (12) that were captured on 4 collection dates (March, May, July, September) (Table 2). For a comprehensive list of all animals captured refer to Davidson et al. (1999). No oocysts were found in samples collected from P. leucopus. Perognathus flavus was the most abundant rodent captured from both treatment and reference sites and Eimeria reedi was the most prevalent species of coccidia observed. Small sample sizes prevented analytical comparisons for March and May collections and no significant difference was found in prevalence of $E$. reedi between July ( 4 mo postrelocation) reference and treatment populations. In September (6 mo postrelocation), E. reedi prevalence was significantly greater $(\mathrm{P}<0.05)$ in recaptured $P$. flavus for the reference population than for the treatment population. Eimeria chobatari and E. reedi oocysts were found in three of the host species in two genera; Dipodomys ordii, D. spectabilis and P. flavus.

\section{DISCUSSION}

This survey of Cynomys gunnisoni in New Mexico documents four previously reported species of eimeriid coccidia, Eimeria callospermophili, E. cynomysis, E. ludoviciani and E. spermophili and two spe- 
TABLE 2.-Number of fecal samples collected, rodent species and Eimeria spp. found in those samples from each of six rodent species captured at the Sevilleta LTER in 1997

\begin{tabular}{lccc}
\hline \hline \multicolumn{1}{c}{$\begin{array}{c}\text { No. samples } \\
\text { with }\end{array}$} & $\begin{array}{c}\text { Rodent spp. } \\
\text { Eimeria } \text { spp. }\end{array}$ & Eimeria spp. & $\begin{array}{c}\text { Nomples } \\
\text { with } \\
\text { Eimeria } \text { spp. }\end{array}$ \\
\hline Dipodomys ordii & 21 & Perognathus flavus & 320 \\
E. chobotari & 2 & E. chobotari & 1 \\
E. reedi & 1 & E. reedi & 110 \\
Dipodomys spectabilis & 16 & Both & 1 \\
E. chobotari & 1 & Peromyscus leucopus & 14 \\
E. liomysis & 1 & None & - \\
E. mohavensis & 1 & Onychomys arenicola & 8 \\
E. reedi & 2 & Unsporulated (one morph) & 4 \\
& & Reithrodontomys megalotis & 12 \\
& & E. arizonensis & 2 \\
\hline
\end{tabular}

cies that are new host records, E. pseudospermophili and E. vilasi. Previously, Thomas and Stanton (1994), in Utah, found E. callospermophili (and/or E. morainensis), E. beecheyi, E. spermophili, E. bilamellata (later synonymized with E. cynomysis, Wilber et al., 1998), E. larimerensis and E. cynomysis infecting C. gunnisoni.

Prevalence of infection with Eimeria species declined significantly in the postrelocation population of Cynomys gunnisoni. Without an established population of C. gunnisoni on the Sevilleta LTER before relocation of animals from Albuquerque, we can only postulate probable causes for this decline. Because of the short duration of this experiment it is likely these results are due to the cyclic nature of the coccidians. However, the overall prevalence of eimerian infections dropped significantly and not all species of Eimeria contribute equally to this phenomenon.

Of the six species of Eimeria originally found within the prairie dog samples, four were relatively rare and were not recovered from the relocated prairie dogs. The two remaining species, E. callospermophili and E. vilasi, had high prevalences within the prerelocated population that decreased after relocation, though only E. vilasi showed a significant decrease. Seville and Stanton (1993), working with another sciurid (Spermophilus variegatus grammurus) believed high eimerian prevalences indicated little or no host immune response to the eimerian infection.

Wilber et al. (1994) found a sharp decline in Eimeria adaensis (=E. vilasi, Wilber et al., 1998) in Townsend's ground squirrels Spermophilus townsendii during summer months which is consistant with the decline of $E$. vilasi in the relocated prairiedog population. However, a significant increase in $E$. callospermophili also was observed, an event not seen the prairie dog population. These authors attributed the patterns to aquired immunity and the seasonal weather cycle. Others have shown that the effects of stress, such as that caused by decline in host population and changes in the environment relating to host diet change, can regulate eimerian prevalences within a host populations (Long, 1982; Crompton, 1987; Allen et al., 1998; Oppliger et al., 1998; Lafferty and Kuris, 1999). One or all of these had a significant influence on the prevalences of E. callospermophili and E. vilasi in the prairie dog population.

In addition, it is thought that differences in reproductive potentials and responses of infective oocysts under varying abiotic conditions are mechanisms by which the prevalence of eimerian species varies within a host population (Fuller et al., 1995; Stanton et al., 1992). This idea is important when analyzing the decline we found in prevalences of eimeriid coccidia in prairie dog and Perognathus flavus populations. Within the sympatric rodent community, only $P$. flavus was caught in numbers great enough for statistical analysis. No significant difference of the prevalences in Eimeria reedi was found between treatment and reference recaptures until 6 mo after the prairie dog relocation. Because the effects of species variability and host number can be accounted for, this may represent a minimal time frame 
necessary for an effect of disturbance, such as species introduction, to be detected on eimerian prevalences.

Relocation was associated with a significant decline in the coccidia fauna of the prairie dog Cynomys gunnisoni. This study gives insight into the potential effects of relocating a population of $C$. gunnisoni and, in particular, revealed no transfer of prairie dog coccidians to the resident rodent population at the time of this study. While both Eimeria vilasi and E. callospermophili infect multiple genera within the Marmotini tribe, they have yet to be found to cross family boundaries (Wilber et al., 1998). Future long-term studies that include multiple control and treatment populations are necessary in order that a comprehensive picture of this host-parasite system can be made.

Acknowledgments. - We thank A. Davidson, Dr. B. Parmenter, M. Friggens, J. Aragon, A. Leach, L. Yau and my colleagues in the Duszynski Laboratory for their assistance. Financial support was provided by a NSF (Biotic Survey and Inventory) Grant \#DEB 9505025 to DWD. This project was supported by the UNM Sevilleta LTER Program and is Publication No. 186 (NSF, BSR-88-11906; DEB-95-9411976).

\section{Literature Cited}

Allen, P. C., H. D. Danforth AND P. C. Augustine. 1998. Dietary modulation of avian coccidiosis. Inter. J. Parasitol., 28:1131-1140.

Christensen, R. 1996. Analysis of variance, design, and regression: applied statistical methods, 1st ed. Chapman and Hall, London: New York. 587 p.

Crompton, D. W. T. 1987. Host diet as a determinant of parasite growth, reproduction and survival. Mammal. Rev., 17:117-126.

Davidson, A. D., R. R. Parmenter AND R. G. Gosz. 1999. Responses of vegetation and small mammals to a reintroduction of Gunnison's prairie dogs. J. Mammal., 80:1311-1324.

DE Vos, A. J. 1970. Studies on the host range of Eimeria chinchillae De Vos and Van der Westhuizen, 1968. Onderstepoort J. Vet. Res., 37:29-70.

Duszynski, D. W. AND P. G. Wilber. 1997. A guidline for the preparation of species descriptions in the Eimeriidae. J. Parasitol., 83:333-336.

Fuller, C. A., J. HefNer AND E. Wrosch. 1995. Oocyst output, periodicity, and immunity of two deer mouse (Peromyscus maniculatus) eimerians (Eimeria arizonensis and Eimeria delicata). J. Parasitol., 81:187-194.

HendRICHS, L. D. 1977. Host range characteristics of the primate coccidian Isospora aratopitheci Rodhain, 1933 (Protozoa: Eimeriidae). J. Parasitol., 63:32-35.

Hnida, J. A. AND D. W. DuszynKsI. 1999. Cross-transmission studies with Eimeria arizonensis, E. arizonensis-like oocycst and Eimeria langebarteli: host specifictiy at the genus and species level within the Muridae. J. Parasitol., 85:873-877.

LAFFERTY, K. D. AND A. M. KURIS. 1999. How environmental stress affects the impacts of parasites. Limn. Oceanogr., 44:925-931.

Long, P. L. 1982. The biology of the coccidia. University Park Press, Baltimore, Maryland. 502 p.

LONG, M. E. 1998. The vanishing prairie dog. National Geographic, 194 (April):118-130.

Miller, B., G. Ceballos and R. Reading. 1994. The prairie dog and biotic diversity. Conserv. Biol., 8: $677-681$.

Oppliger, A., J. Clobert, J. Lecomte, P. Lorenzon, K. Boudjemadi and J. H. B. Alder. 1998. Environmental stress increases the prevalence and intensity of blood parasite infection in the common lizard Lacerta vivpara. Ecology Letters, 1:129-138.

SEville, R. S. 1997. Eimeria spp. (Apicomplexa: Eimeriidae) from Black- and White-tailed Prairie Dogs (Cynomys ludovicianus and Cynomys leucurus) in Central and Southeast Wyoming. J. Parasitol., 83:166-168.

AND N. L. Stanton. 1993. Eimerian guilds (Apicomplexa: Eimeriidae) in Richardson's (Spermophilus richardsonii) and Wyoming (Spermophilus elegans) ground squirrels. J. Parasitol., 79: 973-975.

Stanton, N. L., L. M. Shults, M. Parker and R. S. Seville. 1992. Coccidian assemblages in the Wyoming ground squirrel, Spermophilus elegans elegans. J. Parasitol., 78:323-328.

Thomas, D. M. And N. L. Stanton. 1994. Eimerian species (Apicomplexa: Eimeriina) in Gunnison's 
prairie dogs (Cynomys gunnisoni zuniensis) and rock squirrels (Spermophilus variegatus grammurus) from Southeastern Utah. J. Helm. Soc. Wash., 61:17-21.

TODD, K. S., JR. AND D. M. HAMmOND. 1968a. Life cycle and host specificity of Eimeria callospermophili Henry, 1932 from the Uinta ground squirrel Spermophilus armatus. J. Protozool., 15:1-8.

- AND 1968b. Life cycle and host specificity of Eimeria larimerensis Vetterling, 1964, from the Uinta ground squirrel, Spermophilus armatus. J. Protozool., 15:268-275.

Upton, S. L., C. T. Mcallister, D. B. Brillhart, D. W. Duszynski and C. W. Wash. 1992. Crosstransmission studies with Eimeria arizonensis-like oocysts (Apicomplexa) in New World rodents of the genera Baiomys, Neotoma, Onychomys, Peromyscus and Reithrodontomys (Muridae). J. Parasitol., 78:406-413.

Wilber, P. G., B. Hanelt, B. Van Horne and D. W. Duszynski. 1994. Two new species and temporal changes in the prevalence of eimerians in a free-living population of Townsend's ground squirrels (Spermophilus townsendii) in Idaho. J. Parasitol., 80:251-259.

- D. W. Duszynski, S. J. Upton, R. S. Seville and J. O. Corliss. 1998. A revision of the taxonomy and nomenclature of the Eimeria spp. (Apicomplexa; Eimerdiidae) from rodents in the tribe Marmotini (Sciuridae). Syst. Parasitol., 39:113-135.

M. M. RYAN ${ }^{1}$, K. H. DECKER AND D. W. DUSZYNSKI ${ }^{2}$, Department of Biology, University of New Mexico, Albuquerque 87131.

Submitted 13 March 2000; accepted 2 October 2000.

\footnotetext{
${ }^{1}$ Corresponding author. e-mail: mryan@unm.edu

2 e-mail: eimeria@unm.edu
} 